\title{
LA IDEA DEL HOMBRE EN EL DERECHO
}

\author{
Guillermo J. MAÑÓN GARIBAY
}

Resumen:

En el presente texto se reflexiona sobre la manera en que se puede hablar de una idea de hombre en el derecho, así como de los cambios que esta idea de hombre ha sufrido en las principales etapas de su desarrollo histórico.

Palabras clave:

Hombre, sociedad, derecho, modernidad, liberalismo, antropología filosófica.

Abstract:

In this article, the author discusses how we might talk about the notion of "man" in the law and considers the different changes this notion has had through different stages of its historical process.

Keywords:

Man, Society, Law, Modernism, Liberalism, Philosophical Anthropology. 
No es fácil aclarar de una manera simple aquello que sea el derecho; por un lado, puede decirse, desde un punto de vista lingüístico, que el derecho constituye una estructura de sentidos gracias al sistema de prescripciones objetivas que elabora; por otro lado, el derecho, entendido en su efectividad pragmática, es al mismo tiempo parte del entorno vital, o sea law in action. ${ }^{1}$ Como tal, el derecho siempre constituirá un repertorio de normas que deben ser obedecidas y, en su caso, impuestas por la fuerza. Pero antes de un factor social coactivo, el derecho representa un factor conciliador de los distintos intereses sociales, porque es evidente que las normas del derecho se encuentran determinadas tanto por factores económicos como no económicos, así como por relaciones fácticas de poder, tradiciones y costumbres. Estos múltiples intereses que afectan al derecho representan las distintas fuerzas sociales que es necesario equilibrar por medio de reglamentos, los cuales definirán los espacios legítimos para la acción y las garantías de la libertad y paz social. Con esto, el derecho se convierte en un elemento y expresión de la cultura, parte de la representación del mundo y de la idea del hombre.

En la forma en que el derecho regula la vida en comunidad con una intención normativa evidenciará, directa o indirectamente, una idea de hombre, i.e. una idea de cómo es visto y concebido el hombre, de cuáles son sus capacidades, de qué es aquello que le corresponde por naturaleza, de hacia dónde deba ser dirigido o alejado y protegido. E, inversamente, con esta idea de hombre, el derecho determinará los derechos subjetivos, impondrá obligaciones, concederá facultades, creará reglas procesales e instituciones con actividad normativa.

Esto quiere decir que la idea de hombre es resultado de un proceso dialéctico, a partir del cual se crean reglas concretas y principios generales que sirven de apoyo al orden

1 El clásico de la sociología del derecho es Eugen Ehrlich y su obra Grundlegung der Soziologie des Rechts, Munich und Leipzig 1913. En el siglo XX y el nuestro, quien a seguido desarrollando la misma idea es Wolfgang Hein en su obra Rechtstatsachenforschung Heute, Universitätsverlag Konstanz 1986. 
social, el cual a su vez promueve la reflexión filosófica y nutre esa misma idea de hombre a lo largo del tiempo. De esta manera, el derecho, tanto por su aspecto teórico como práctico, constituye un factor de la conciencia del hombre mismo, ya que guía el quehacer humano de manera racional, forjando la conciencia humana frente al deber.

El estudio sobre la idea del hombre en el derecho se centrará principalmente en la edad moderna y contemporánea. La justificación del análisis de la idea del hombre en la tradición europea reside en que en este perímetro cultural, incluso en el ámbito mundano, se verificaron permanentemente cambios de grandes consecuencias en la conformación del derecho. Esto se prefigura ya en los albores de la cultura griega, con la fundación de la vida urbana como centro del despliegue civilizatorio, ${ }^{2}$ llegando a su apogeo en el siglo XVIII de nuestra era con la redacción de muchas legislaciones europeas que no entienden más al derecho como el producto de una forma de vida, o sea, derecho legitimado a través de la tradición y las costumbres, sino que comienzan a entenderlo como la consciente persecución de metas para conformar un mejor orden social, apuntalado en una autoridad legitimamente reconocida y en una deliberada idea de hombre, de su naturaleza, misión y forma de vida.

1. Los antropólogos ${ }^{3}$ afirman que el principio que regía la vida en las comunidades de cazadores y recolectores consistía en la adaptación al medio natural, según una distribución natural del trabajo y de la riqueza. Esto supuso el estancamiento e invariabilidad de las sociedades primitivas, aunque también su supervivencia. Las sociedades dirigidas

2 Véase el libro III de la obra de Fustel de Coulanges, La ciudad antigua: estudio sobre el culto, el derecho, las instituciones de Grecia y Roma, Santa Fe de Bogotá, 1997.

3 Leakey, R. E., The Making of Mankind, Londres, WC1, 1981, capítulo VI. 
por este principio de vida, organizador de la producción y distribución de la riqueza, recibieron el nombre de sociedades acaudaladas o sociedades de la abundancia, ${ }^{4}$ porque las necesidades de toda la comunidad se veían por igual satisfechas y adaptadas a lo que su medio ambiente ofrecía.

Sin embargo, esto tuvo que cambiar al momento de volverse el hombre sedentario. Si bien no se sabe con certeza cuándo este principio de las comunidades de cazadores y recolectores fue desbancado por otro distinto, si se puede afirmar que el principio que lo sustituyó fue el del mandato. ${ }^{5} \mathrm{El}$ sociólogo alemán Alexander Rüstow ${ }^{6}$ sugiere que fue en el neolítico, por causa de la invasión de tribus montadas a caballo y que, en razón de esto, pudieron someter a las sociedades nómadas y semi-sedentarias gracias a su movilidad y enorme fuerza (dando con esto lugar al mito de los centauros). Lo importante es que a partir de ese momento, las sociedades se estructuraron de forma piramidal, igual que las construcciones que en ese entonces erigieron, desplazando al principio de la adaptación, propio de las sociedades primitivas, estratificadas según las diferencias de parentesco (padre mandan sobre los hijos).

La dinámica del principio de mandato coadyuvó a organizar la sociedad desde la autoridad del rey o gobernante, sin que esto implicara la desaparición completa de la tradición y costumbres. ${ }^{7}$ Gracias a la dinámica de este principio fue posible al hombre construir grandes palacios y conquistar vastos imperios, pero sobre todo fue posible realizar cambios deliberados en la trayectoria de la sociedad mediante la coerción, o sea, mediante un mecanismo de imposición amenaza/castigo.

4 Malinowski, B., Argonauts of the Western Pacific, Nueva York, 1922.

5 Heilbroner, R., 21st Century Capitalism, Cambridge, 1993.

6 Rüstow, A., (1885-1963) Ortsbestimmung der Gegenwart. Eine universalgeschichtliche Kulturkritik, 3 Bände, 1950-1957. En especial véase Band 1: "Ursprung der Herrschaft".

7 Adam Smith afirma que en el antiguo Egipto era un sacrilegio ejercer un oficio distinto al de los padres. 
¿Cómo asegurar su poder la casta dominante en un tiempo de instituciones débiles?, ¿cómo se protege la sociedad misma de incurrir en la anomia total? El sociólogo norteamericano Peter Berger sugiere que la institución central, en las primera sociedades de mandato, fue la religiosa, porque a través de ella aseguraba la autoridad del soberano una validez definitiva frente a cualquier intento de desobediencia o derrocamiento. Los dioses se convirtieron en los garantes del orden social al convertir el derecho a mandar en algo incuestionable.

También por eso se quiso presentar, en las sociedades arcaicas, el orden legal de la sociedad como equivalente al orden cósmico (dentro del cual la sociedad humana representaba un microcosmos ${ }^{8}$ ). En las comunidades medievales, e incluso en las modernas, este orden legal se presentó en forma de ius-naturalismo. En ambos casos, se trataba de dotar de estabilidad al orden social, creado por el hombre, "proyectándolo" en el universo o en los dioses.

2. ¿Qué idea de hombre fabricó el derecho a partir de su atadura a la religión y naturaleza? En los siglos que corresponden a la alta Edad Media en Europa, ${ }^{9}$ el derecho partía de la premisa incuestionable del hombre como criatura divina, lo que lo determinaba a guardar una cierta relación con su creador a través de la reglamentación de su actuar cotidiano. De esta asunción se desprendía que el derecho era una parte de la interpretación religiosa del orden del mundo (i. e. del mundo como creación divina), porque ahí residia precisamente su fundamento y se derivaban los deberes del hombre, fiel para con una iglesia y doctrina, enemigo de las ofensas a Dios y solícito a socorrer a sus correligionarios.

En ese contexto, la herejía suponía un peligro para el fundamento del orden político. Por ello, era tarea del poder

8 De esta forma se representa la tragedia ática en la antigua Grecia. Véase Sófocles, Edipo, y Antígona.

9 La respuesta a la pregunta: ¿qué es la Alta Edad Media y qué siglos abarca?, la encuentro en Harmut Boockmann, Das Mittelalter, Munich, 1989. 
civil evitar la disolución de la fe y la difusión de doctrinas falsas, castigar la blasfemia y vengar las ofensas contra la majestad divina. El castigo y purga de los crímenes y omisiones suponían el desagravio divino, el camino hacia la concordia social y la salvación humana.

1. Esa idea del hombre impregnada de religión encontrará su fin en Europa Occidental con el cisma religioso protestante, el cual liberó al derecho de su atadura religiosa. La pregunta que guió a los juristas en tiempos de la Reforma protestante fue: ¿cómo es posible en el futuro la convivencia de hombres de distintas iglesias? Porque la división de la cristiandad significó una disensión en las cuestiones teológicas ${ }^{10}$ que no transigía con acuerdo alguno y, por tanto, exigía un Estado y derecho secular. Ciertamente, se intentó conservar la unidad en la fe mediante el uso de la espada y el fuego, pero esto sólo trajo mucho sufrimiento y nuevas controversias sobre el empleo legitimo de la violencia. Por ejemplo, Desiderio Erasmo y el joven Lutero - para el viejo Lutero es otra cosa- opinaban que sólo mediante el diálogo se debería recuperar a los herejes y errados en la fe, pero nunca mediante el uso la fuerza. ${ }^{11}$

La imposibilidad de una solución teológica al conflicto religioso decidió que le fuera cedida al señor feudal la preeminencia religiosa dentro de su territorio (cuius regio, eius religio), y, con el tiempo, gracias al beneficium migrationis producto de la Paz de Ausburgo (1555), se concedió mayor libertad al individuo para decidir a cuál iglesia deseaba pertenecer, como también libertad para que cada cual juzgara la rectitud de su fe (libertad de conciencia). Por último, la

10 Recuérdese que Lutero sólo aceptó dos de los siete sacramentos.

11 Discursos contra la guerra en tiempos donde la guerra era la principal actividad de los reyes se encuentran en: Erasmus von Rotterdam, Die Klage des Friedens (Guerela Pacis), Darmstadt, 1995, volumen V. Más tarde Rousseau, en el Contrato social, volverá a arremeter contra la idea de que la fuerza hace derecho. Véase Rousseau, J., J., Contrato social, libro I, capítulo 1. 
Paz de Westfalia (1648) concedió libertad y derecho a la privacidad de la fe.

Si bien estos derechos o libertades fueron escasos, representaron, sin embargo, un cambio de paradigma, porque estos derechos correspondian a cada individuo por razón de su fe y conciencia personal, y lo desligaban de la dependencia jurídica de la comunidad y del soberano. El señor feudal no podía oponerse a que un vasallo abandonara su territorio si la razón para ello era el libre ejercicio de su fe dentro de la iglesia de su preferencia. Con esto, el derecho a libre elección de la iglesia prevalecía sobre cualquier otra obligación jurídica. Georg Jellinek afirmó, con razón, que la libertad religiosa fue el origen, si bien en principio muy insipiente, del derecho a la libertad moderna, porque independizó al individuo de la comunidad y lo ubicó en el primer plano del interés jurídico. A partir de ese momento, el individuo sería tomado en sí mismo antes de reparar en cualquier vínculo social que nutriera. Jellinek concluye que con esto se sembró la semilla en el derecho secular. ${ }^{12}$

2. ¿Qué idea de hombre alberga este nuevo derecho secular? Por un lado, se continuará pensando, como en el pasado antiguo y medieval, que el hombre vive necesariamente en sociedad, o sea, como un animal social y político, pero ahora no de manera abstracta, remitido a una comunidad general, sino concretamente, como miembro de una sociedad determinada por su libre voluntad. Y como miembro de esa comunidad elegida libremente, tendrá cada individuo derechos y obligaciones definidos por lazos de libertad y dependencia. Estos lazos de libertad y dependencia determinan su estatus legal, su lugar dentro de la comunidad, su mayor o menor participación política y, por tanto, sus distintos niveles de compromiso social. La sociedad por entero será una societas civilis cum imperio, dentro de la cual el "imperio" estará diseminado en concretas relaciones socia-

12 Jellinek, G., Die Erklärung der Menschen- und Bürgerrechte, Munich, 1997, pp. 46-51. 
les y no más concentrado en el poder del soberano. ${ }^{13}$ De esta forma, el hombre, al socializar, cumplirá con múltiples obligaciones sociales, que en parte se entenderán como relaciones de poder y en parte como relaciones estructuradas por la cooperación. Estas relaciones - fueran de carácter doméstico o público, fueran generales o exclusivas de las autoridades - tenían la capacidad de construir el sujeto social como un sujeto de derecho, definiendo la identidad de cada cual dentro de la comunidad.

La consecuencia inmediata de esta capacidad de construir el sujeto de derecho y otorgarle su identidad fue la ingerencia del poder político en la vida privada. El derecho no sólo cargó con la responsabilidad de garantizar la paz y seguridad pública, sino, además, arremetió con la tarea de normar la dirección de la vida personal de todos sus miembros.

En un principio, la dirección de la vida privada abarcó los oficios (división del trabajo) y todo comportamiento público; constriñendo el carácter regulativo del derecho a las acciones de "interés común". Pero, más tarde, esta normatividad, producto del interés común, se extiendo más allá de la prosperidad social y llegó al "bienestar moral" de cada individuo, ${ }^{14}$ en forma de una nueva concepción de orden, vigilancia y castigo. Por "bienestar moral" se entendió una vida decente y honorable, sin ociosidad y desperdicio, sin riñas o borracheras. Y como se le consideró esencial para la realización del interés común, se creyó necesario revestir a la policía de derechos inapelables para conservar un orden de comportamiento público, paz y tranquilidad, aunque contraviniera la libertad de contrato. La intención era tutelar el bienestar de los súbditos dentro de una sociedad organizada corporativamente. ${ }^{15}$

13 Ciertamente, no todos los autores proclamaron esto mismo. Véase Hobbes, Th., Leviatan.

14 Que recuerda a la $\varepsilon v \delta \alpha \imath \mu o v ı \alpha$ aristotélica.

15 Ésta fue una consecuencia de las ideas del "organicismo", teoría que sostuvo que las sociedades son organismos análogos a los de los seres vivos y que sus distintas partes funcionan con relación al todo de modo semejante a las de aquéllos. 
En esta concepción jurídica, la imagen del hombre es reconocible de inmediato. El hombre aparece como un individuo dentro de una comunidad dotada de orden, que permite la orientación hacia una vida moralmente buena y conforme al interés común. Este hombre debe ser protegido y tutelado debido a los peligros que deparan su naturaleza y capacidad de error, por eso, sus derechos no representan libertad y autonomía, sino tan sólo vida conforme la recta moral e interés común. Evidentemente, este orden jurídico se encuentra sostenido en una policía, en la relevancia social del castigo y en conceptos éticos que determinan las tareas y obligaciones de cada cual. 16

3. Si se pregunta por el fundamento filosófico de esta idea de hombre en el derecho se debe mencionar, por una parte, a Aristóteles: el hombre es, según su naturaleza y fi-

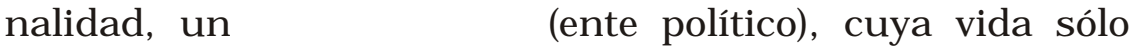
puede realizarse en comunidad, ante todo en oıко (casa, hogar) Пo $\lambda \iota \varsigma$ (ciudad), con el fin de alcanzar la $\varepsilon v \delta \alpha \imath \mu o v i \alpha$ (felicidad). Esta idea de hombre adquirió validez definitiva en el pensamiento jurídico y político a partir de la recepción del estagirita en el siglo XII y XIII, y su vigencia permaneció más allá de la Reforma protestante. ${ }^{17}$ Pero para entender la idea del hombre en el derecho, que parte de la consideración del individuo y sirve de fundamento y explicación de la sociedad, a la manera como lo hicieron los teóricos clásicos del derecho racionalista Hobbes y Locke, es necesario traer a colación el paradigma filosófico del alemán Samuel von Pufendorf, 18 quien desplazó paulatinamente a Aristóteles y

Esta teoría fue expuesta en el Leviatán, por Hobbes, y desarrollada en las leyes de la evolución por Herbert Spencer en su obra Political Writings, en The History of Political Thought, Cambridge, 1993.

16 No hace falta decir que en esta tónica fue redactada la obra Leviatan de Thomas Hobbes.

17 Por ejemplo, el aristotelismo protestante de Philipp Melanchthon, o el católico de Francisco Suárez.

18 Pufendorf, S., von., Über die Pflicht des Menschen und Bürgers nach dem Gesetz der Natur, Frankfurt a. M., 1994. 
Tomás de Aquino al realizar la fundamentación teórico-jurídica del individuo en el derecho.

Con la Revolución Francesa se consumó el cambio de paradigma jurídico que afectó la idea de hombre y la organización de su vida social. Rebasando las fronteras del pensamiento francés, el cambio de paradigma representó el punto culminante de la concepción del hombre como un ser individual. El contenido de ese cambio, del orden de ideas políticas y sociales de la Revolución Francesa, fueron preparadas en el pensamiento filosófico de la ilustración, en especial por los teóricos del derecho racional del siglo XVII, y culminaron en la proclamación de los derechos del hombre y del ciudadano de 1789.

1. El punto de partida de la teoría racional del derecho fue la idea de un hombre individual, libre, valiéndose por sí mismo en estado natural, previo a cualquier relación y realidad social que pudiera calificarlo como "un-ser-paraalguien". La peculiaridad de este movimiento político fue el de poner las cosas de cabeza - para usar una expresión de Hegel19_, o sea, el concebir el mundo como un producto del pensamiento del hombre. ${ }^{20}$ Por eso, las relaciones y dependencias sociales no antecedían al hombre, antes bien lo suponían y sólo comenzaban a existir gracias a su decisión voluntaria de crearlas con la finalidad de conservarse y desarrollarse individualmente. Curiosamente, en la era de la ciencia experimental, el potencial emancipatorio de la teoría racional no perdió fuerza por el hecho de carecer de pruebas de la existencia empírica de un estado natural previa al contrato social.

19 Hegel, G-W, F., Vorlesung über die Philosophie der Geschichte, Stuttgart, 1999, capítulo III, parte cuarta.

20 Derivado del racionalismo cartesiano: Todo lo que es racional es real. Véase Williams, B., Descartes. The Project of Pure Enquiry, Reino Unido, 1978. En especial el capítulo III, Cogito and sum. 
La nueva idea de hombre desplazó a la antigua, deslegitimándola y asentando un nuevo concepto de libertad humana que - como se dijo- encontró su expresión en la Declaración de los Derechos del Hombre y del Ciudadano. El primer artículo de la declaración asienta de manera lapidaría la nueva idea de hombre en su condición natural: "Los hombres nacen y permanecen libres e iguales en derechos". Mientras el segundo artículo expresa la finalidad de toda sociedad civil: "La finalidad de toda asociación política es la conservación de los derechos naturales e imprescriptibles del hombre. Tales derechos son la libertad, la propiedad, la seguridad y la resistencia a la opresión”. El artículo cuarto es el modelo fundamental para la formación futura del orden jurídico: "La libertad consiste en poder hacer todo aquello que no perjudique a otro: por eso, el ejercicio de los derechos naturales de cada hombre no tiene otros límites que los de garantizan a los demás miembros de la sociedad el goce de estos mismos derechos. Tales límites sólo pueden ser determinados por la ley".

Este último artículo tuvo enromes consecuencias, ${ }^{21}$ a saber: haber colocado la libertad abstracta del individuo en el lugar de la libertad concreta, producto de las relaciones de poder en el ámbito social y político. Esta libertad, entendida como libertad del individuo autónomo, se convertirá en punto de partida y referencia para el orden jurídico, alrededor del cual sería erigido en lo sucesivo sus potestades y responsabilidades. Esto significó la apoteosis del hombre individual, cuya realización se extendió durante todo un siglo, con diferentes intensidades y no sin la superación de muchas dificultades, disolviendo paulatinamente los vínculos sociales que impedian la autonomía completa de cada cual.

2. Para exponer el alcance de la nueva idea del hombre en el derecho, hay que destacar dos particularidades. Primeramente, en el citado artículo cuarto de la Declaración de

21 Como en caso del filósofo y economista inglés John Stuart Mill. Véase la introducción al primer capítulo de la obra On Liberty de J. S. Mill. 
los Derechos del Hombre y del Ciudadano, se presenta la red de relaciones sociales como obstáculo del desarrollo individual. Marx se refirió a esto en su crítica a la Declaración de los Derechos del Hombre de 1793.22

Los límites dentro de los cuales cada cual, sin peligro de lastimar a su prójimo, se puede mover, ha sido determinada por la ley, como se establecen los límites de dos campos con ayuda de una cerca. Se trata de la libertad del hombre aislado a la manera como está una mónada consigo mismo (...). El derecho del hombre a libertad se basa no en el vínculo de los hombres con los hombres, sino antes bien en el aislamiento de los hombres entre ellos mismos. Es el derecho al aislamiento. ${ }^{23}$

Marx critica la falta de solidaridad del concepto de libertad individual, así como su orientación positivista respecto del prójimo cuando se le toma como principio jurídico estructurador de la sociedad, porque descansa sobre la hipótesis del egoísmo racionalista y de la competencia como promotora del progreso. ${ }^{24} \mathrm{El}$ concepto de libertad, si bien no niega el carácter social, lo desplaza al ámbito de la moral individual, porque al ser incapaz de estructurar dentro del orden jurídico la obligación de solidaridad, queda relegado a la esfera discrecional de cada individuo, como afirma J. S. Mill. "Dichas máximas son estas: primera, que el individuo no debe dar cuenta de sus actos a la sociedad, si

22 En 1793 se redactó una nueva Declaración de Derechos del Hombre y del Ciudadano, precediendo a la Constitución francesa del 24 de junio de ese año. En ésta se establecía mayor importancia de los derechos individuales sobre los sociales, prohibía la esclavitud y señalaba el derecho a sublevarse contra la tiranía. En 1795 se redactó una Declaración de Derechos del Hombre y el Ciudadano más, que precedió a la Constitución francesa del año III (calendario napoleónico). Ésta era más parecida a la de 1789 que a la de 1793, pretendía evitar la posibilidad de instaurar una democracia social y confirmaba la libertad económica.

23 Marx, K., Frühschriften, traducción del autor. Obra consultada en el libro digital Marx / Engels, Ausgewählte Werke, Digitale Bibliothek, Band 11.

24 A la manera como se expone en Pufendorf el egoísmo racionalista, o en el inglés Bernard Mandeville en su obra The Fable of the Bees; más tarde también Jeremias Bentham, padre del utilitarismo egoísta, en su obra Offences Against One's Self. 
no interfiere para nada los intereses de ninguna otra persona más que la suya”. ${ }^{25}$

La segunda peculiaridad reside en que, bajo este concepto, el derecho comprende la existencia del hombre como si estuviera libre de determinaciones físicas o metafísicas, como si su condición social o su fe en Dios fueran irrelevantes en su orientación o resistencia en la elección, o como si no existieran privilegios o desventajas de nacimiento.

En otros términos: la sociedad no reconoce a los competidores rechazados ningún derecho legal o moral a quedar exentos de esta clase de sufrimientos; y sólo se siente llamada a intervenir cuando los medios empleados para lograr el éxito son contrarios a los que el interés general permite, es decir, el fraude o la traición, y la violencia. ${ }^{26}$

Eso no importa más; antes bien, pareciera que cada cual busca y elige sus determinaciones sin recibir del derecho indicación alguna para la elección, sin plantear ni responder la cuestión de cuál sea la razón de la libertad, sin formular ninguna idea positiva y vinculante sobre la misma o sobre la sociedad, "...la sociedad, como sociedad, no tiene por qué declarar malo lo que no afecta más que al individuo; ella no puede ir más allá de la disuasión, y una persona podrá ser tan libre para disuadir como otra para persuadir". 27

Por eso, el lugar del derecho ético material lo ocupará el derecho formal a la libertad, abandonando al individuo a su libre arbitrio. De esta forma, el hombre no tiene ninguna meta a dónde dirigirse, ya que no se trata de una libertad propia de su naturaleza - como en el caso aristotélico- o que cuente con un determinante religioso, educativo, inclu-

26 Idem.

27 Idem. 
so hedonista. ${ }^{28}$ Antes bien, esta nueva libertad coloca al hombre frente a la elección abierta de una religión, educación, o experiencia placentera, sin especificar los riesgos y responsabilidades contraídos.

"Los hombres son libres de conducirse en la vida según sus opiniones, sin que los demás se lo impidan física o moralmente, y siempre que sea a costa de su exclusivo riesgo y peligro. Esta última condición es, naturalmente, indispensable". 29

3. Franz Schnabel ${ }^{30}$ afirmó que el siglo XIX fue el siglo de los juristas, porque gracias a la Revolución Francesa se convirtió el orden jurídico en un derecho de la sociedad civil burguesa. Este paradigma jurídico se extendió dentro del ámbito civil, sobre todo dentro de la vida económicamente activa, transformando la policía, preparada únicamente para la prevención y defensa, abandonando la tutela del bienestar privado. Esto quiere decir que el orden jurídico se centró en el individuo, revestido de principios como el de igualdad y libertad, destruyendo todos los privilegios, anulando monopolios y gremios, legitimando el lucro y la libertad de contrato, ofreciendo a todo mundo el ejercicio de cualquier oficio, abriendo la economía a la libre competencia, garantizando la propiedad privada y el derecho a herencia. Por eso se dice que este era el derecho de la sociedad civil acomodada, burguesa, que contaba con altos beneficios económicos y propiedad privada.

Sin embargo, este nuevo orden jurídico encontró su límite natural en la familia y el matrimonio, porque no era posible adaptar familia y matrimonio al modelo de la libertad y autonomía sin anular su sentido primigenio. Por eso, aquí,

28 Ciertamente, el utilitarismo es una variante del hedonismo clásico. Sin embargo, Mill desea, paradójicamente, que el deseo y bien individual sea a la vez el del mayor número.

29 Mill, J. S., op. cit., nota 21, capítulo III.

30 Schnabel, F., Deutsche Geschichte im Neunzehnten Jahrhundert, Band 1: Die Grundlagen, Band 2: Monarchie und Volkssouveränität, Band 3: Erfahrungswissenschaften und Technik, Band 4: Die religiösen Kräfte, Munich, Deutscher Taschenbuch Verlag (dtv), 1998. 
en el ámbito familiar, prevaleció la antigua idea de hombre, con todos sus nexos éticos y jurídicos, deberes y obligaciones. Y aquí también continuó el debate, hasta entrado el siglo XX, sobre la autonomía del individuo, como acusa una mirada somera sobre el sentido del matrimonio y la familia hoy día. ${ }^{31}$

El análisis de estos dos casos mostrará la repercusión que tuvo en la idea del hombre el orden jurídico acuñado por la Revolución Francesa. ${ }^{32}$ Las cuestiones que se platearon fueron las siguientes: ¿cómo deben ser interpretados y conceptualizados matrimonio y familia dentro del modelo liberal?, ¿cómo debe entenderse la autoridad paternal frente a la autonomía de los hijos?, ¿es posible seguir entendiendo (y justificando), dentro del contexto del derecho dogmático, al matrimonio como una institución supra-individual en la cual el lazo conyugal impone obligaciones y construye dependencias, anulando la libre disposición de la voluntad individual protegida por el derecho?, ¿debe la institución matrimonio constituir un fin en sí misma y ser portadora de una voluntad fundada en la unión amorosa de dos personas, de tal forma que sea imposible destruir el contrato matrimonial?

A principios del siglo XX se planteó de una manera distinta la autoridad paternal dentro del derecho civil privado: "El niño está obligado frente a los padres, aunque no sometido a su autoridad. La realización de la debida obediencia

31 Döner, H., Industrialisierung und Familienrecht, Berlín 1974, pp. 67-118.

32 En México, el proyecto ilustrado, impulsado desde España por las Reformas Borbónicas (1750-1780), impactaría a la sociedad mexicana hacia el último cuarto del siglo XVIII. Con ello se abriría el horizonte de la cultura y la educación mexicana al ideario alentado por los positivistas europeos y mexicanos. Gómez Farias fue quien introdujo en la escuela básica el empleo de los "catecismos políticos". La finalidad era instruir a la niñez en la doctrina cívica para convertirlos en ciudadanos virtuosos. La práctica de escribir catecismos políticos prevaleció a lo largo del siglo XIX, compitiendo con los catecismos religiosos en el desarrollo nuevos contenidos educativos. 
representa el hecho de ceder su poder individual de sujeto autónomo al padre". 33

Puede preguntarse qué idea de padre, de su potestad paterna, se establece con esto. Porque aquí se muestra claramente el cuestionamiento de dicha autoridad paterna, quien dentro del derecho romano sustentaba la patria potestas (ius in re) $\mathrm{y}$, por tanto, la prole aparecía como materia para el ejercicio del derecho a dominio, o sea, la prole como objeto del derecho del padre para ejercer sobre ella el poder de su voluntad.

Cuando Friedrich Carl von Savigny, importante jurista del siglo XIX por la redacción del sistema jurídico dogmático, definió el derecho subjetivo como el poder de un individuo de hacer valer su voluntad sin afectar a los demás, dispuso con ello la escisión del derecho y la moral, o sea, el alejamiento de los conceptos y contenidos de consideraciones morales. La justificación de Savigny procede de la siguiente manera: "El derecho sirve a la moral, pero no en tanto impele al cumplimiento de sus mandamiento, sino en cuanto asegura el libre desarrollo de su fuerza (Kraft) contenida en cada voluntad individual". ${ }^{34}$

Aquí se originó la concepción actual de derecho subjetivo, entendido conforme a supuestos filosóficos sobre la persona libre e individual, construida en su autonomía gracias a la protección que le brinda el orden jurídico y resultado de las relaciones que sostienen con otros individuos. Se le podría preguntar a Savigny qué sucede cuando no se desarrolla esa fuerza moral o cuando entra en conflicto con el derecho, sobre todo porque para Savigny la familia y el matri-

33 Antaño existía la llamada "facultad de corregir a los hijos". Según los defensores de la Convención sobre Derechos del Niño, esta disposición atentaba contra el carácter de sujeto de derecho del menor de edad y propiciaba el maltrato infantil, en la medida que no quedaba claro que debía entenderse por "facultad de corregir". Hoy día, la actual "facultad de corregir a los hijos" pretende adecuarse a la Convención sobre Derechos del Niño, en la medida que impide la proliferación del maltrato infantil (al respecto, ver concepto de violencia del documento "Aspectos centrales de la violencia intrafamiliar desde un punto de vista legal").

34 Savigny F. C., von, System des heutigen römischen Rechts, versión en castellano: Sistema del derecho romano actual, Granada, 2005, p. 221. 
monio representaban relaciones naturales, por tanto morales, que no son reguladas en su contenido por el derecho sino únicamente para determinar las condiciones de su existencia. De este modo, se afirmaría que la educación de la prole cae dentro de la autoridad de los padres, aunque no por mandato jurídico, sino por el vago e indefinido poder moral que tiene el padre sobre el niño. Con base en ese poder moral, el niño deviene intocable posesión del padre, aunque, paradójicamente, sin el estatus de siervo sometimiento a los derechos del soberano. La autoridad paternal sería para Savigny el resultado de su dignidad moral frente a los hijos.

Este sistema dogmático de derecho civil, concebido como derecho autónomo, es un ejemplo de indeterminación de obligaciones vinculantes, así como de los derechos alcanzados mediante el cumplimiento de esas obligaciones, porque se niega al derecho la posibilidad de regular el contenido de las relaciones familiares. Esto tuvo históricamente como consecuencia el que la autoridad del padre frente al niño se viera limitada, incluso mediante la intervención del derecho penal. ${ }^{35}$

4. Con esto puede verse cómo la concepción de los principios del derecho dogmático presentan problemas. En principio, podría pensarse que una teoría jurídica que pone en el centro de sus prioridades a la persona libre y autónoma hace lo correcto para el desarrollo de la vida en común cuando delimita la libertad de cada cual. Pero, en realidad, nunca ha atendido a las consecuencias respecto de la economía y sociedad; porque si el orden jurídico tiene su composición central en la igualdad, la libertad individual en forma de libertad de contrato, de salario y en la garantía de la propiedad privada, incluyendo el derecho de herencia, no puede resolver las antinomias que esto origina. La razón re-

35 En la Convención sobre los Derechos del Niño de la ONU se lee: Artículo 16: 1. "Ningún niño será objeto de injerencias arbitrarias o ilegales en su vida privada, su familia, su domicilio o su correspondencia ni de ataques ilegales a su honra y a su reputación. 2. El niño tiene derecho a la protección de la ley contra esas injerencias o ataques". 
side en que este orden jurídico activó procesos que promovieron la desigualdad entre los hombres, como el de libre enriquecimiento, derivando de ahí la garantía jurídica sobre la propiedad privada y el derecho de herencia, lo que constituía la condición para la desigual participación en el desarrollo social, y el derecho de herencia la condición para perpetuar esta diferencia a la siguiente generación. De esta forma, la desigualdad social de los hombres fue, paradójicamente, la consecuencia de un orden jurídico construido sobre el derecho a la igualdad. La desigualdad dio lugar a la falta de libertad, porque dentro de la tendencia del desarrollo técnico e industrial, logrado a través del empleo del capital privado, se fortaleció el antagonismo social, en una época de gran crecimiento poblacional, ${ }^{36}$ provocando que la mayoría careciera de las condiciones sociales necesarias para realizar su libertad.

En el siglo XIX hubo múltiples testimonios de las incongruencias del nuevo modelo jurídico y que llevaron a movimientos populares como el de 1848, la llamada "primavera de los pueblos". ${ }^{37}$ A los obreros pareció la declaración de libertad, igualdad y solidaridad una burla. Y no obstante que el derecho no podía permanecer callado, ya que su tarea principal es la impartición de justicia, antes incluso que la de proveer principios sociales y concepciones sobre libertad o igualdad, fueron razones políticas las que propiciaron una

36 Crecimiento poblacional europeo, dentro y fuera de Europa a partir del siglo XIX, tuvo consecuencias importantes, como un mayor desarrollo industrial y las políticas imperialistas europeas. Véase La Europa del siglo XIX, Fondo de Cultura Económica, 1971, de Goeffrey Bruun. Este autor afirma que en 1815 había 200 millones de europeos y para 1914 se elevo la población a 460 millones. Esto se debió a que la tasa de crecimiento aumento entre 3\% y $4 \%$ anual durante todo un siglo, pero a la vez disminuyó la tasa de mortandad. Durante el mismo periodo (caída de Napoleón y el comienzo de la Primera Guerra Mundial) emigraron 40 millones de europeos y se establecieron en otros continentes. También los descendientes europeos que habitaban ultramar se multiplicaron por 10: en 1815 había 20 millones y en 1914 eran 200 millones de descendientes europeos. Uno de cada 3 europeos vivía en ultramar. Y si a esto se suman los europeos que vivían en el viejo continente con sus emigrantes y descendientes, entonces se tiene que un tercio de la población mundial era europea.

37 Sobre la "Primavera de los pueblos" de 1848, véase Hobsbawn, E. J., La era del capitalismo, el capítulo: "El preludio revolucionario", Madrid, 1977. 
reforma que, como es sabido, tuvo lugar en el ámbito del derecho laboral, específicamente con la prohibición del trabajo infantil. Esto representó, en el sentido estricto del liberalismo, un ataque a la facultad de decisión del padre de familia sobre sus hijos, así como la limitación de la jornada laboral a diez horas al día representó un ataque contra la libertad de contrato. ${ }^{38}$ A las reformas laborales siguieron, entre otros, el reconocimiento a la libertad de asociación y el inicio de la seguridad social por vejez, invalidez, enfermedad, toda vez, se pensó, que si el derecho no puede impartir justicia por lo menos que ofrezca una defensa ante las formas más elementales de injusticia. ${ }^{39}$

Esto desembocó en el desarrollo de un derecho laboral como una especialidad independiente, de manera tal que apareció una especie de orden paralelo al derecho civil que promovió una idea distinta de hombre, a saber: el hombre que debe ser protegido por el Estado, en contraposición a la personalidad autónoma que actúa por cuenta propia dentro del marco del derecho formal. ${ }^{40}$ Ahora, el hombre debería ser protegido de determinados fuerzas sociales, de los riesgos naturales de la vida ante los cuales es difícil previsión alguna, custodia de las oportunidades de vida a través de disposiciones sociales de emparejamiento o igualación (educación y salud gratuita, seguro de desempleo, etcétera. ${ }^{41}$ Correspondientemente, se formaron nuevas figuras jurídicas que no seguían el dogma de la voluntad libre y autónoma, sino que se orientaban fuertemente a la situación real

38 Sobre las condiciones y subsecuentes reformas laborales, véase Hobsbawn, E. J., idem.

39 Todo esto, evidentemente, hace referencia al "Estado de Bienestar", término acuñado durante el Segundo Imperio Francés por los republicanos que criticaban el espíritu individualista de ciertas leyes. En Alemania se le utilizó hacia 1870 por los "socialistas de cátedra" para describir el sistema de Otto von Bismarck en materia social; y a mediados del siglo XX, se empleó el término inglés welfare state (literalmente: "estado de bienestar") para referirse a las políticas keynesianas de posguerra.

40 Zacher, H., F., "Verrechtlichung im Bereich des Sozialrechts", en Kübler, F. (ed.), Verrechtlichung von Wirtschaft, Arbeit und sozialer Solidarität, Baden-Baden, 1984. Especialente las páginas 35-72.

41 Ibidem, pp. 54-72. 
y al ritmo de crecimiento de la sociedad industrial de masas. Este desarrollo repercutió en el derecho civil, al grado que hoy día se habla frecuentemente de un proceso de re-moralización del derecho o del modelo social liberal. ${ }^{42}$

\section{IV}

Para analizar la idea del hombre en del derecho contemporáneo se puede tomar como punto de partida el año 1948, año de la Declaración Universal de los Derechos Humanos, reacción ante el terror y vacío de derecho causados por el nacionalsocialismo alemán y el fascismo italiano.

El primer artículo de la declaración dice: "Todos los seres humanos nacen libres e iguales en dignidad y derechos y, dotados como están de razón y conciencia, deben comportarse fraternalmente los unos con los otros". A parte de los conceptos igualdad, libertad y solidaridad, aparece en primer plano el concepto de dignidad humana. Podría pensarse que con esto tiene lugar una reconciliación entre Aristóteles y el modernismo, sobre todo si se analizan dos artículos más de esta misma Declaración, a saber: artículo 28 y 29.43

1. Lo que el artículo 28 establece coincide con la declaración de Herrenchiemsee: "El Estado existe para los hombres/ciudadanos, no los ciudadanos para el Estado". ${ }^{44}$ Esa declaración tiene su razón de ser en los abusos del totalita-

42 Ibidem, p. 42.

43 Artículo 28: "Toda persona tiene derecho a que se establezca un orden social e internacional en el que los derechos y libertades proclamados en esta Declaración se hagan plenamente efectivos". Artículo 29: "1. Toda persona tiene deberes respecto a la comunidad, puesto que sólo en ella puede desarrollar libre y plenamente su personalidad".

44 Del 10 al 23 de agosto de 1948 una comisión de expertos, denominada "Convención Constitucional”, se dio cita en el lago Herrenchiemsee, en la Baviera Alta, con el fin de elaborar un proyecto de Ley Fundamental. Las deliberaciones se realizaron bajo la impronta de las experiencias del sistema constitucional de Weimar y la dictadura de Hitler. En la Convención de Herrenchiemsee se volvió a plantear la cuestión, ya discutida en Weimar, de la naturaleza jurídica de los derechos fundamentales. Véase al respecto Weimar, Ein Lesebuch zur deutschen Geschichte 1918-1933, Munich, 1997. 
rismo fascista, aunque significa la negación de la idea del hombre tal y como se encuentra en la Politica de Aristóteles y que determinó el derecho de la antigua Europa, en donde el hombre gracias a los vínculos con la comunidad llega a su propio desarrollo.

El artículo 28 de la Declaración Universal de los Derechos Humanos y la citada declaración de Herrenchiemsee tienen un paralelismo con el segundo artículo de la Declaración de los Derechos del Hombre y el Ciudadano de 1789: "La finalidad de toda asociación política es la conservación de los derechos naturales e imprescriptibles del hombre. Tales derechos son la libertad, la propiedad, la seguridad y la resistencia a la opresión". Lo que esto significa es que el Estado es el instrumento que garantiza la libertad como derecho subjetivo humano. Con lo que pierde vigencia el que el hombre exista en función de la comunidad política y que gracias a ello llegue a la realización de lo que constituye su naturaleza. ${ }^{45}$ Lo que representa nuevamente un decisivo impulso a la expansión de la libertad individual, en el sentido de libertad subjetiva, así como un impulso hacia la individualización de cualquier relación humana. Por tanto, los derechos fundamentales han sido concebidos como derechos a la libertad subjetiva del individuo y no como derechos a la libertad de la comunidad o de redes sociales.

¿Cuáles pueden ser las consecuencias del enfrentamiento del artículo 28 y 29 de la Declaración Universal?

Primero, un problema con el concepto y realización de la libertad misma: el derecho garantiza frente al poder del Estado un espacio de libertad y autonomía, cuyo ejercicio está dispuesto por el derecho mismo, pero bajo la discrecionalidad de cada individuo. El ejercicio de esta libertad se encuentra restringido por límites externos a esa libertad, pero nunca en razón de su contenido o demandas. Esto condiciona una construcción e interpretación de los distintos ámbitos del orden jurídico general en dirección a un for- 
talecimiento del ámbito de la libertad subjetiva y el retroceso de vínculos jurídicos en su contenido objetivo.

La definición de la dignidad humana, expresada en los derechos fundamentales, es su libertad, pero libertad no entendida como libertad metafísica o libertad trascendental u objetiva, sino como libertad subjetiva del individuo en el sentido de libertad de elección y libertad para "autodeterminación".

2. La fuerte subjetivización del orden legal en nombre de una libertad individual ha puesto en marcha un proceso de desarrollo normativo que dota de dirección y perfil a la idea de hombre en el derecho.

a) El orden constitucional, embebido de los derechos fundamentales, remite a la subjetividad individual entendida como ámbito de acción protegida por los derechos fundamentales cuyo fin es la realización de la libertad. Este ámbito no garantiza poseer contenido determinado alguno, sino antes bien su posibilidad de adquirir uno. Los hombres aparecen dentro del orden jurídico como puestos en libertad en sus dos sentidos: real y formal. De esta manera, los hombres se encuentran frente a una enorme oferta de elección, sin considerar que en ese contexto de ofertas los hombres disponen tanto de visiones del mundo creadas en la religión como visiones espirituales y éticas o culturales, dentro de las cuales opera su libertad de elección. ${ }^{46}$ Para realizar una elección hace falta contar con una identidad a partir de la cual adquiera sentido las posibilidades de elección; entonces, la libertad no se encuentra al principio sino al final de la construcción de una identidad cultural.

Pero, ¿de dónde puede, y debería, venir una orientación la construcción de la identidad en un Estado laico, correspondiente a una sociedad plural, que tiene como imperativo

\footnotetext{
$46 \mathrm{El}$ "fantasma" terrorífico de Marx tiene mucho que decir al respecto con su teoría del valor religiosos o "valor fetiche" desarrollada en el Capital, Crítica a la economía política, sección primera: "Mercancía y dinero", capítulo primero "La mercancía". Pero si traer a la memoria a Marx es demasiado "temerario", entonces véase al respecto Gehlen, Arnold, Der Mensch. Seine Natur und Stellung in der Welt, segunda parte, pp. 131-180.
} 
respetar la libertad sin la posibilidad de proponer una visión previa del mundo como antaño fue la religiosa?, ¿es posible hablar en este contexto de la relevancia de una herencia cultural? Además, es necesario tomar en cuenta que la precaria situación de la educación (sobre todo de la educación básica) no permite construir una identidad con una orientación determinada que permita más tarde hacer uso efectivo de la libertad.

b) El desarrollo de la vida económica acusa también múltiples ejemplos problemáticos, porque aquí también recibió un inmenso impulso la liberación y destrucción de las barreras que contenían fuerzas e intereses egoístas y de grupo. Hoy día es posible el enriquecimiento sin límite, tanto individual como social, resultado de la liberación de las fuerzas del mercado, del rechazo de la economía planificada y fundamento del bienestar material. No es este el momento de hacer una descripción exhaustiva, basta con remitir a la lectura de las cuatro "libertades del mercado" civil formuladas en el contrato de la Comunidad Europea ${ }^{47}$ para darse cuenta que lo que allí está en juego son las múltiples formas de libertad para el enriquecimiento individual.

Bajo este tenor, se independizo económicamente el individuo (libertad de mercado) y se le convirtió en fundamento de la vida económica. Se dijo que en la medida en la que las fuerzas productivas, en especial aquellas que buscan capital rentable y competencia en el mercado, emprendieran la liberación y demolición de los obstáculos y barreras - lo que sucedió a través de reglamentaciones jurídicas y tratados internacionales-, entonces tendría lugar un mejor posicionamiento del individuo según sus intereses y fuerzas productivas, porque de esa manera seguiría habiendo una liberación y expansión de las capacidades individuales. ${ }^{48}$

Este proceso económico pretendía dirigir los acontecimientos según la racionalidad económica estructurada por

47 1) Libre tránsito de mercancías, 2) libre tránsito de servicios, 3) libre asentamiento, 4) libre tránsito de capital y financiero.

48 Véase el trabajo de Heilbroner, R., op. cit., nota 5, pp. 23-73. 
la lógica funcional de sistemas. ${ }^{49}$ En ese contexto económico, los economistas comenzaron a hablan sin escrúpulos del "capital humano", lo que mostró que el valor de los hombres se mediría con relación a su utilidad y contribución a la productividad, o sea, a su obtención de plusvalía y capacidad de competencia. Entendidos como "capital humano", los hombres deberán ser baratos, flexibles, actualizados permanentemente, reciclables, sin relevancia alguna como personas. Hoy día, cualquiera encuentra una enorme gama de posibilidades de educación y especialización, con el fin de que sus conocimientos y capacidades amaestradas sean de valor mercantil, valor de cambio en el mercado laboral. Las exigencias del proceso económico impuso - e impone- al individuo pretensiones desmedidas en cuanto a flexibilidad, aprendizaje permanente, optimización "voluntaria” y total movilidad para la conservación y elevación de la productividad. 50

Por causa de la globalización, la lógica funcional de sistemas proyecta al hombre a una dimensión más grande, a aquello que Hans Freyer describía como sistema secundario. ${ }^{51}$ Esto significa que el sujeto aparece en este sistema secundario no como sujeto con libertad sino simplemente como portador de funciones, o sea, como una herramienta sucedánea según necesidades y exigencias. Por eso, el sujeto representa dentro del sistema funcional mismo (en este caso, de la economía, o del proceso económico crecientemente más globalizado) un "sistema secundario" con el fin de crear capital y ganancia (entendido esto último como factor determinante).

c) Una variante más de este desarrollo individualista se deja ver en el derecho penal. Por un lado, ha habido un cambio hacia la descriminalización del orden de vida moral: aquello que no amenazan o perjudican directamente bienes

49 Freyer, H., Theorie des gegenwärtigen Zeitalters, Stuttgart, 1956, pp. 79 y ss.

50 Un análisis interesante sobre los efectos sociales del neoliberalismo se encuentra en la obra de Montes, P., El desorden neoliberal, Madrid, 1996, pp. 23-30.

51 Freyer, H., op. cit., nota 49. 
privados, protegidos por el derecho, ha sido retirado del círculo de los delitos punibles y con ello dejado a la libre consideración individual de cada cual. 52

El derecho penal, en el sentido del liberalismo, persigue una clara orientación hacia lo individual (prevención/rehabilitación); por tanto, la doctrina jurídica que le sirve de fundamento, parte de un pensamiento sobre el bienestar general, pero enfrentando las obligaciones sociales del individuo bajo la consideración de los derechos del mismo a bienes privados.

3. En el análisis del orden jurídico actual se revela la idea del hombre como la de un ser individual necesitado de protección y ayuda, con el fin de que pueda ejercer su libertad personal. El hombre debe ser protegido socialmente contra los riesgos de la vida: enfermedad, vejez, pobreza, invalidez, y, en cierta medida, también protegido contra pérdida de la plaza de trabajo y desempleo total. Pero hay que decir que no es por iniciativa contractual de cada cual que se toman precauciones legales y se crean sistemas de seguridad, porque aquí también operan las disposiciones a la manera de los "sistemas secundarios": los hombres se entienden únicamente dentro del sistema de producción, como herramienta de trabajo, que es necesario mantener en óptimas condiciones de operación. Por eso, no se puede decir que haya una re-moralización del derecho privado, porque la manera como se exige y concede la solidaridad, dentro de los numerosos sistemas de seguridad y ayuda del Estado, es tomando al individuo sin referirlo a la familia o a la comunidad, como tampoco a obligaciones concretas de solidaridad social. La ayuda se organiza y realiza gracias al dinero, o sea, a través de contribuciones monetarias. Y sobre esta base se construyen organizaciones y modelos de comportamiento abstractos que aportan y reclaman las "presta-

52 Tendencia que se observa desde los ensayos de J. S. Mill, por ejemplo: On Liberty, capítulo V. Ahí distingue Mill entre dos tipos de contrato y dos tipos de libertades, a saber: legal y moral. El contrato legal no puede ser incumplido, el moral sí. De ahí que la libertad legal esté restringida y la moral no. 
ciones monetarias", dando lugar a administraciones burocráticas y no solidarias o altruistas. ${ }^{53}$ Esto tiene ciertamente muchas ventajas, ante todo el de insertarse dentro de la tendencia del derecho actual a individualizar las relaciones de convivencia; por eso, este sistema de protección social no se opone a la tendencia individualizadora de las relaciones jurídicas, sino que procede de una manera paralela.

De esta manera, se conceptualiza al hombre a través de regulaciones públicas, según funciones y roles establecidos de manera estándar: "estudiante becado CONACYT", "beneficiario de apoyo para la vivienda INFONAVIT", "solicitante de empleo del observatorio laboral de la STPS", "minusválido CONAPRED protegido por la beneficencia social", "adulto mayor afiliado al INAPAM", etcetera. Desde esta concepción jurídica, aparece el individuo bajo la especie de "caso" para ser tratado sólo como mandan las reglas vigentes.

4. Si el concepto de dignidad humana es un concepto vago es debido a que aquello que se proponga como "dignidad humana" depende de lo que se entienda por hombre, de la idea de hombre. De esta manera, la validez de la idea del hombre aristotélica o de la idea del hombre del modernismo no depende del concepto de dignidad humana; antes bien lo contrario, ese concepto de dignidad humana debe ser propuesto a partir de una idea de hombre que sirva de fundamento. Sin embargo, actualmente palidece crecientemente la idea de hombre en el derecho con el consecuente menoscabo de su capacidad de dirigir y orientar la vida hacia su realización concreta y correcta. Con ello se pierde un importante componente del derecho que dota de sentido a la pregunta de si es posible construir actualmente una idea del hombre en el derecho.

En el mejor de los casos, la idea de hombre prevaleciente hoy día será la idea de hombre autónomo e individual, producto de la Revolución Francesa y de la economía de libre

53 Sobre este procesos social véase Fromm, E., Psicoanálisis de la sociedad contemporánea, México, 1970, capítulo V: "La sociedad del siglo XX: cambios cacterológicos”, pp. 96-130. 
mercado. Pero no es posible ignorar que el orden social muestra una enorme heterogeneidad que sugiere también la imposibilidad de concebir el orden legal desde una idea de hombre común y uniforme. Tal vez a esto se deba la creciente resonancia del sistema teórico de Niklas Luhmann, quien constituye un indicador de la expansión de la "nueva realidad". Para Luhmann ${ }^{54}$ el individuo no aparece más como punto de partida de la reflexión jurídica, sino como construcción, como producto de la comunicación o resultado de un sistema de estructuras, de comportamientos y relaciones.

En el futuro no se puede excluir la posibilidad de que el derecho vigente llegue a extraviarse por carecer de una idea coherente de hombre. La discusión actual sobre tecnología genética y bioética ofrece indicios sobre esto. Tómese como ejemplo la sentencia sobre el aborto legal en la ciudad de México, aquel que se practica poco antes de las doce primeras semanas, donde no se menciona la idea de hombre desde la cual se dirimió el problema. También sirva de ejemplo la decisión en algunos países desarrollados para crear y poner a disposición de la investigación científica embriones; o aquel otro problema bioético que tiene relación con el diagnóstico de pre-implantes embrionarios. ${ }^{55}$ Está por verse en qué medida tendrá lugar una discusión sobre estos temas en el futuro desde la concepción de una idea de hombre (y no se descarta que, aunque ese sea el caso, se le acuse de servir como superestructura ideológica que oculta los intereses del poder).

54 Luhmann, N., "Soziologie als Theorie sozialer Systeme", Soziologische Aufklärung, Oplade, 1993, pp. 50-66.

55 Un estudio actual sobre esta problemática es el de Steenblock, V., Praktische Philosophie. Grundpositionen und anwendungsprobleme der Ethik, Stuttgart, 2008, t. II, pp. 189-220. 